Check for updates

Cite this: RSC Adv., 2019, 9, 14750

Received 20th March 2019

Accepted 25th April 2019

DOI: 10.1039/c9ra02163a

rsc.li/rsc-advances

\section{Four new Zn(II) and Cd(II) coordination polymers using two amide-like aromatic multi-carboxylate ligands: synthesis, structures and lithium-selenium batteries application $\uparrow$}

\author{
Qiuxia Cheng, ${ }^{a}$ Luzhu Qin, ${ }^{a}$ Chunxian Ke, ${ }^{a}$ Jianen Zhou, ${ }^{a}$ Jia Lin, ${ }^{\text {ac }}$ Xiaoming Lin, (D) *ab \\ Gang Zhang ${ }^{\mathrm{d}}$ and Yuepeng Cai ${ }^{\star a}$
}

Four new coordination polymers, $\left\{\left[\mathrm{Zn}(3-\mathrm{PBI})\left(\mathrm{H}_{2} \mathrm{O}\right)\right] \cdot 2 \mathrm{DMF}\right\}_{n}(1),[\mathrm{Cd}(3-\mathrm{PBI})(\mathrm{DMF})]_{n}(2),\left\{\left[\mathrm{Zn}_{4}\left(\mu_{4}-\mathrm{O}\right)(4-\mathrm{PBI})_{3}\right]\right.$. $3 D M F\}_{n}$ (3), $\left\{\left[\mathrm{Cd}_{4}(4-\mathrm{PBI})_{4}\left(\mathrm{H}_{2} \mathrm{O}\right)_{6}\right] \cdot 13 \mathrm{H}_{2} \mathrm{O}\right\}_{n}(4)$, have been constructed from two isomeric flexible multicarboxylate ligands, 3- $\mathrm{H}_{2} \mathrm{PBI}=5$-(3-(pyridin-3-yl)benzamido)isophthalic acid and 4- $\mathrm{H}_{2} \mathrm{PBI}=5$-(3(pyridin-4-yl)benzamido)isophthalic acid. Structural analysis reveals that compound 1 is a onedimensional (1D) ladder-like chain assembled by $\mathrm{Zn}\left({ }^{\prime}\right)$ ions and $3-\mathrm{PBI}^{2-}$ ligands, which further extend into a 3D supramolecular structure through $\pi \cdots \pi$ stacking and interlayer $(\mathrm{O}-\mathrm{H} \cdots \mathrm{O})$ hydrogen bonding interactions. In compound 2, $\mathrm{Cd}^{2+}$ metal ions are connected by carboxylate groups to form $\left[\mathrm{Cd}_{2}(\mathrm{COO})_{4}\right]$ secondary building units (SBUs). The whole framework possesses a quadrilateral channel and constitutes a unique 3D (3,6)-connected rutile net with the Schläfli symbol of $\left(4^{2} \cdot 6^{10} \cdot 8^{3}\right)\left(4 \cdot 6^{2}\right)_{2}$. As for 3 , $\mathrm{Zn}(॥)$ ions are bridged by one $\mu_{4}-\mathrm{O}$ and six carboxylate groups to form a tetranuclear $\left[\mathrm{Zn}_{4}\left(\mu_{4}-\mathrm{O}\right)(\mathrm{COO})_{6}\right]$ cluster, resulting in a rare $(3,9)$-connected $3 \mathrm{D}$ network. Compound 4 has an appealing 2D layered architecture involving two distinct topologies in the crystal structure, stacking in an unusual ABBABB mode (where $A$ represents $\left(4 \cdot 8^{2}\right)$ topology and $B$ denotes kgd topology). Moreover, compound 2 is prepared as a support for active selenium through a melt-diffusion method. The obtained $\mathrm{Cd}-\mathrm{CP} / \mathrm{Se}$ electrode can be tested for lithium-selenium batteries and shows an initial capacity of $514 \mathrm{~mA} \mathrm{~h} \mathrm{~g}^{-1}$ and a reversible capacity of $200 \mathrm{~mA} \mathrm{~h} \mathrm{~g}^{-1}$ at $1 \mathrm{C}$ after 500 cycles. The good storage performance of $\mathrm{Cd}-\mathrm{CP} / \mathrm{Se}$ demonstrates it to be a prospective cathode material for lithium-selenium batteries.

\section{Introduction}

Over past decades, coordination polymers (CPs), as crystalline functional materials with intriguing network structures by selfassembly of metal ions/clusters and organic ligands, ${ }^{1-5}$ have rapidly progressed due to their versatile utility in potential applications, such as proton conductors, ${ }^{6}$ heterogeneous catalysts, ${ }^{7}$ magnetism, ${ }^{8}$ gas storage and separation, ${ }^{9}$ luminescence sensors, ${ }^{\mathbf{1 0}}$ and supercapacitors. ${ }^{\mathbf{1 1}}$ However, their crystallization

${ }^{a}$ School of Chemistry and Environment, South China Normal University, Guangzhou Key Laboratory of Materials for Energy Conversion and Storage, 510006, P. R. China.E-mail: linxm@scnu.edu.cn; caiyp@scnu.edu.cn

${ }^{b}$ School of Environment and Energy, South China University of Technology, Guangzhou, Guangdong 510006, China

${ }^{c}$ Key Laboratory of Theoretical Chemistry of Environment, Ministry of Education, School of Chemistry and Environment, South China Normal University, Guangzhou 510006, P. R. China

${ }^{d}$ State Key Laboratory of Supramolecular Structure and Materials, College of Chemistry, Jilin University, Changchun 130012, P. R. China

$\dagger$ Electronic supplementary information (ESI) available. CCDC 1855125-1855130 for ligands and compounds 1-4. For ESI and crystallographic data in CIF or other electronic format see DOI: 10.1039/c9ra02163a is a complicated process and is dependent on many experimental factors, including the nature of the organic linkers, the coordination preferences of the metal ions, the ratios of the raw materials, the temperature and solvents, as well as the possible inclusion of guest components within the coordination lattice. ${ }^{12,13}$ Among these factors, selection of the right ligands with a certain functionality and flexibility could be the most rational way to obtain predictable frameworks and properties. $^{\mathbf{1 4 , 1 5}}$ The semi-rigid multitopic organic ligands, such as amide-connected $\mathrm{N}$-heteroaromatic carboxylate ligands, methylene- or ether-linked aromatic tetracarboxylate ligands, ${ }^{\mathbf{1 6}-19}$ have attracted much attention in the formation of porous or nonporous CPs, since the freely rotating amide/methylene/ether groups can adopt a variety of conformations via bending, stretching, or twisting. Despite the great achievements that have been made, it is still a challenge for crystal engineers to rationally design and synthesize new coordination polymers with certain characteristics.

We have been working on the self-assembly of crystal engineering and application in the field of energy conversion and storage. ${ }^{20-25}$ As a continuation of our research work, herein, we 
chose two semirigid amide-linked aromatic polycarboxylate ligands and successfully synthesized four new coordination polymers, $\left\{\left[\mathrm{Zn}(3-\mathrm{PBI})\left(\mathrm{H}_{2} \mathrm{O}\right)\right] \cdot 2 \mathrm{DMF}\right\}_{n}(\mathbf{1}),[\mathrm{Cd}(3-\mathrm{PBI})(\mathrm{DMF})]_{n}(\mathbf{2})$, $\left\{\left[\mathrm{Zn}_{4}\left(\mu_{4}-\mathrm{O}\right)(4-\mathrm{PBI})_{3}\right] \cdot 3 \mathrm{DMF}\right\}_{n}(3),\left\{\left[\mathrm{Cd}_{4}(4-\mathrm{PBI})_{4}\left(\mathrm{H}_{2} \mathrm{O}\right)_{6}\right] \cdot 13 \mathrm{H}_{2} \mathrm{O}\right\}_{n}$ (4) by two isomeric multi-carboxylate ligands, 5-(3-(pyridin-3-yl) benzamido)isophthalic acid and 5-(3-(pyridin-4-yl)benzamido) isophthalic acid (Scheme 1). Compound $\mathbf{1}$ features a 1D ladder-like chain. While compound 2 is a 2 -fold interpenetrating $(3,6)$-connected rutile net. Compound 3 has a rare $(3,9)$-connected $3 \mathrm{D}$ network. In the case of $\mathbf{4}$, it reveals intriguing 2D layers structure involving two distinct topologies of $\left(4 \cdot 8^{2}\right)$ and $\mathbf{k g d}$ nets. Moreover, porous compound 2 was evaluated as a host for lithium-selenium batteries. The fabricated $\mathrm{Cd}-\mathrm{CP} / \mathrm{Se}$ electrode presents an initial capacity of $514 \mathrm{~mA} \mathrm{~h} \mathrm{~g}^{-1}$ at $1 \mathrm{C}$ and a reversible capacity of $200 \mathrm{~mA} \mathrm{~h} \mathrm{~g}$ after 500 cycles.

\section{Experimental section}

\section{General information}

Organic ligands 5-(3-(pyridin-3-yl)benzamido)isophthalic acid (3- $\left.\mathrm{H}_{2} \mathrm{PBI}\right)$ and 5-(3-(pyridin-4-yl)benzamido)isophthalic acid (4$\mathrm{H}_{2} \mathrm{PBI}$ ) were synthesized according to reported methods. ${ }^{26,27}$ Infrared spectra were collected with $\mathrm{KBr}$ pellets on a Nicolet/ Nexus-670 FT-IR spectrometer. Elemental analyses were obtained by a PerkinElmer 240 elemental analyzer. Thermogravimetric analyses (TGA) were conducted on a Netzsch Thermo Microbalance TG $209 \mathrm{~F} 1 \mathrm{Libra}$ from room temperature to $900{ }^{\circ} \mathrm{C}$ with a heating rate of $10{ }^{\circ} \mathrm{C} \min ^{-1}$ under $\mathrm{N}_{2}$ atmosphere. Powder X-ray diffraction patterns (PXRD) were recorded on a Bruker D8 Advance diffractometer with a $\mathrm{Cu}$ target tube and a graphite monochromator.

\section{Preparation of compounds 1-4}

Compounds 1 and 2 were synthesized as follows: a mixture of 3$\mathrm{H}_{2}$ PBI (18 mg, $0.05 \mathrm{mmol}$ ), DMF (3 mL), water $(3 \mathrm{~mL})$, $\mathrm{Zn}\left(\mathrm{NO}_{3}\right)_{2} \cdot 6 \mathrm{H}_{2} \mathrm{O}(59 \mathrm{mg}, 0.2 \mathrm{mmol})$ for 1 and $\mathrm{Cd}\left(\mathrm{NO}_{3}\right)_{2} \cdot 4 \mathrm{H}_{2} \mathrm{O}$ ( $24 \mathrm{mg}, 0.1 \mathrm{mmol}$ ) for 2 were sealed in Teflon-lined autoclaves, respectively. Then the reactants were heated under autogenous pressure at $110{ }^{\circ} \mathrm{C}$ for three days. After cooling to room temperature, crystals were filtered and dried in air. For compounds $\mathbf{3}$ and $\mathbf{4}$, the reaction procedures were similar to those of 1 and 2 but using $4-\mathrm{H}_{2} \mathrm{PBI}$ instead of $3-\mathrm{H}_{2} \mathrm{PBI}$.
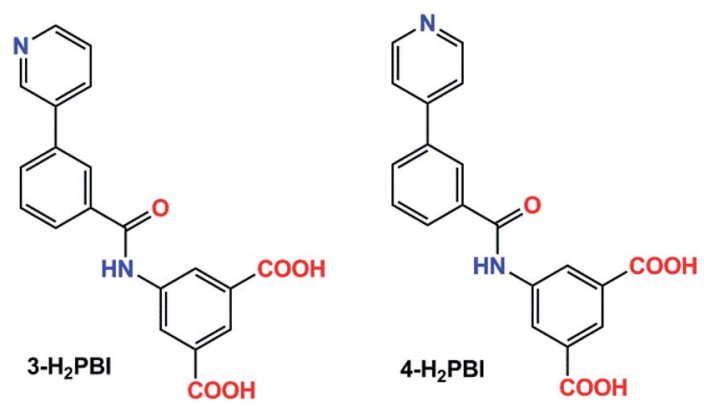

Scheme 1 Structures of $3-\mathrm{H}_{2} \mathrm{PBI}$ and $4-\mathrm{H}_{2} \mathrm{PBI}$ ligands.
$\left\{\left[\mathrm{Zn}(3-\mathrm{PBI})\left(\mathrm{H}_{2} \mathrm{O}\right)\right] \cdot 2 \mathrm{DMF}\right\}_{n}(1)$

Yield: $19.2 \mathrm{mg}$ (65\%, based on ligand). Anal. calcd for $\mathrm{C}_{26} \mathrm{H}_{28} \mathrm{~N}_{4} \mathrm{O}_{8} \mathrm{Zn}$ : C, 52.76; H, 5.11; N, 9.47\%. Found: C, 52.73; H, 5.09; N, 9.51\%. FT-IR (KBr, $\left.\mathrm{cm}^{-1}\right): 3429(\mathrm{~m}), 1667(\mathrm{w}), 1622(\mathrm{~m})$, 1566(vs.), 1436(m), 1378(s), 1068(w), 756(w), 624(m).

\section{[Cd(3-PBI)(DMF) $]_{n}$ (2)}

Yield: $16.1 \mathrm{mg}$ (59\%, based on ligand). Anal. calcd for $\mathrm{C}_{23} \mathrm{H}_{19} \mathrm{~N}_{3} \mathrm{O}_{6} \mathrm{Cd}(\%)$ : C, 50.42; H, 3.86; N, 7.67\%. Found: C, 50.45; H, 3.87; N, 7.69\%. IR ( KBr, $\mathrm{cm}^{-1}$ ): 3429(w), 1660(vs.), 1622(s), 1566(vs.), 1376(s), 1101(w), 784(w), 719(w), 615(w).

\section{$\left\{\left[\mathrm{Zn}_{4}\left(\mu_{4}-\mathrm{O}\right)(4-\mathrm{PBI})_{3}\right] \cdot 3 \mathrm{DMF}\right\}_{n}(3)$}

Yield: $16.0 \mathrm{mg}$ (61\%, based on ligand). Anal. calcd for $\mathrm{C}_{69} \mathrm{H}_{57} \mathrm{~N}_{9} \mathrm{O}_{19} \mathrm{Zn}_{4}$ : C, 52.32; H, 4.01; N, 7.96\%. Found: C, 52.39; H, 3.99; N, 7.93\%. IR (KBr, $\left.\mathrm{cm}^{-1}\right): 3391(\mathrm{~m}), 1658(v s),. 1619(\mathrm{~s})$, 1557(vs.), 1369(vs.), 1104(w), 779(s), 725(s), 601(w).

\section{$\left.\left\{\mathrm{Cd}_{4}(\mathbf{4}-\mathrm{PBI})_{\mathbf{4}}\left(\mathrm{H}_{\mathbf{2}} \mathrm{O}\right)_{6}\right] \cdot \mathbf{1 3 H}_{\mathbf{2}} \mathrm{O}\right\}_{n}(\mathbf{4})$}

Yield: $17.6 \mathrm{mg}$ (63\%, based on ligand). Anal. calcd for $\mathrm{C}_{80} \mathrm{H}_{86} \mathrm{~N}_{8} \mathrm{O}_{39} \mathrm{Cd}_{4}$ : C, 42.87; H, 4.23; N, 5.00\%. Found: C, 42.88; $\mathrm{H}, 4.27$; N, 5.03\%. IR (KBr, $\left.\mathrm{cm}^{-1}\right): 3429(\mathrm{~m}), 1612(\mathrm{~m}), 1557(v s$.$) ,$ 1386(vs.), 1058(w), 855(w), 780(w), 723(w), 624(w).

\section{$\mathrm{X}$-ray structure determination}

X-ray diffraction data were collected with a Bruker APEX II diffractometer (Mo-K $\alpha$ radiation, $\lambda=0.71073 \AA$ ) at $296 \mathrm{~K}$. Absorption correction and space group determination were performed by a multi-scan method implemented in SADABS and XPREP implemented in APEX II, respectively. Structures were solved and refined using direct methods and full-matrix least-squares on $F^{2}$ (SHELXL-2014). ${ }^{28}$ Hydrogen atoms on carbon were calculated with isotropic placement parameters used to calculate hydrogen atoms on carbon in ideal positions. The lattice solvent molecules were highly disordered in the structures of $\mathbf{1}, \mathbf{3}$, and $\mathbf{4}$, and their contributions to scattering were removed using the SQUEEZE routine of PLATON. ${ }^{29}$ Then the generated data was further used to refine the final structures. Crystallographic data and selected bond lengths are summarized in Tables 1 and S1. $\dagger$

\section{Preparation of Cd-CP/Se}

Selenium powder was thoroughly mixed and ground with the prepared compound 2 (Cd-CP) with a mass ratio of $4: 1$. Then the mixture was calcined at $260{ }^{\circ} \mathrm{C}$ in a tube furnace for 6 hours to generate $\mathrm{Cd}-\mathrm{CP} / \mathrm{Se}$.

\section{Electrochemical measurement}

The electrochemical behavior of the as-prepared Cd-CP/Se was performed using coin-type half cells (2032 type) with an Li counter electrode. The working electrode consisted of the active material, super $\mathrm{P}$ carbon black, and $\mathrm{La}^{132}$ binder in a weight ratio of $8: 1: 1$. The slurry was then coated onto a piece of aluminum current collector, which was dried at $55{ }^{\circ} \mathrm{C}$ for $12 \mathrm{~h}$. A 
Table 1 Crystallographic data and structure refinement summary for $3-\mathrm{H}_{2} \mathrm{PBI}, 4-\mathrm{H}_{2} \mathrm{PBI}$ ligands and 1 to 4

\begin{tabular}{|c|c|c|c|c|c|c|}
\hline Compound & $3-\mathrm{H}_{2} \mathrm{PBI}$ & $4-\mathrm{H}_{2} \mathrm{PBI}$ & 1 & 2 & 3 & 4 \\
\hline Empirical formula & $\mathrm{C}_{20} \mathrm{H}_{14} \mathrm{~N}_{2} \mathrm{O}_{5}$ & $\mathrm{C}_{20} \mathrm{H}_{14} \mathrm{~N}_{2} \mathrm{O}_{5}$ & $\mathrm{C}_{26} \mathrm{H}_{28} \mathrm{~N}_{4} \mathrm{O}_{8} \mathrm{Zn}$ & $\mathrm{C}_{23} \mathrm{H}_{19} \mathrm{~N}_{3} \mathrm{O}_{6} \mathrm{Cd}$ & $\mathrm{C}_{69} \mathrm{H}_{57} \mathrm{~N}_{9} \mathrm{O}_{19} \mathrm{Zn}_{4}$ & $\mathrm{C}_{80} \mathrm{H}_{86} \mathrm{~N}_{8} \mathrm{O}_{39} \mathrm{Cd}_{4}$ \\
\hline Formula weight & 362.33 & 362.33 & 589.93 & 545.81 & 1577.88 & 2233.17 \\
\hline Space group & $P 2_{1} / c$ & $P 2_{1} / c$ & $P 2_{1} / c$ & $P 2_{1} / c$ & $C c$ & $C 2 / c$ \\
\hline$a(\AA)$ & $7.402(2)$ & $8.688(3)$ & $15.0740(9)$ & $10.025(3)$ & $22.1033(4)$ & $31.546(4)$ \\
\hline$b(\AA)$ & $22.549(7)$ & $14.484(5)$ & $16.3655(8)$ & $21.289(6)$ & $22.4179(3)$ & $34.778(5)$ \\
\hline$\beta\left({ }^{\circ}\right)$ & $101.137(5)$ & $99.333(6)$ & $94.591(4)$ & $104.201(5)$ & $125.335(2)$ & $119.169(2)$ \\
\hline$\gamma\left({ }^{\circ}\right)$ & 90 & 90 & 90 & 90 & 90 & 90 \\
\hline$V\left(\AA^{3}\right)$ & $1605.0(9)$ & $1642.5(9)$ & $2463.0(2)$ & $2134.9(11)$ & $7098.1(2)$ & $17210(4)$ \\
\hline$Z$ & 4 & 4 & 4 & 4 & 4 & 4 \\
\hline$\rho$ (cald.) $\left(\mathrm{mg} \mathrm{m}^{-3}\right)$ & 1.499 & 1.465 & 1.197 & 1.698 & 1.390 & 1.724 \\
\hline$T(\mathrm{~K})$ & 296 & 296 & 296 & 296 & 296 & 296 \\
\hline$R_{1}[I>2 \sigma(I)]^{a}$ & 0.0453 & 0.0491 & 0.0740 & 0.0444 & 0.0477 & 0.0713 \\
\hline $\mathrm{w} R_{2}$ (all data) $^{b}$ & 0.1049 & 0.1197 & 0.1967 & 0.1124 & 0.1312 & 0.2039 \\
\hline
\end{tabular}

${ }^{a} R_{1}=\sum\left\|F_{\mathrm{o}}|-| F_{\mathrm{c}}\right\| / \sum\left|F_{\mathrm{o}}\right| \cdot{ }^{b} \mathrm{w} R_{2}=\left\{\sum\left[\mathrm{w}\left(F_{\mathrm{o}}{ }^{2}-F_{\mathrm{c}}{ }^{2}\right] / \sum\left(F_{\mathrm{o}}\right)^{2}\right\}^{1 / 2}\right.$, where $\mathrm{w}=1 /\left(\sigma^{2}\left(F_{\mathrm{o}}{ }^{2}\right)+(a P)^{2}+b P\right), P=\left(F_{\mathrm{o}}{ }^{2}+2 F_{\mathrm{c}}{ }^{2}\right) / 3 .{ }^{c}$ Distorted solvent molecules were calculated by the PLATON/SQUEEZE program and confirmed by EA, which is not shown in final formula in CIF files.

Celgard 2300 membrane was used as a separator. $1 \mathrm{M}$ lithium bis(trifluoromethanesulfonyl)imide (LiTFSI) in a mixture of 1,3dioxolane (DOL) and 1,2-dimethoxyethane (DME) (v/v = $1: 1)$ was used as the electrolyte. The electrode coating thickness was about $250 \mu \mathrm{m}$, whereas the Se mass loadings were approximately $1.5-2 \mathrm{mg} \mathrm{cm}^{-2}$. The galvanostatic charge/discharge tests were performed between $1.7 \mathrm{~V}$ and $2.7 \mathrm{~V}$ by using the LAND CT2001A multichannel battery testing system at room temperature. Cyclic voltammetry (CV) measurements were taken on a CHI660C Electrochemical Workstation at a scan rate of $0.1 \mathrm{mV}$ $\mathrm{s}^{-1}$ in a potential range of $1.7-2.7 \mathrm{~V}\left(v s . \mathrm{Li}^{+} / \mathrm{Li}\right)$.

\section{Results and discussion}

\section{Syntheses and structural description and characterization}

Compounds 1-4 were synthesized under similar solvothermal systems at $110^{\circ} \mathrm{C}$ by using two isomeric semi-rigid $\mathrm{N}$-containing multi-carboxylate ligands $\left(3-\mathrm{H}_{2} \mathrm{PBI}\right.$ and $\left.4-\mathrm{H}_{2} \mathrm{PBI}\right)$. Fortunately, crystals of the two ligands were obtained by recrystallization in DMF solvent at ambient temperature and then allowed to stand for one week, which was confirmed by X-ray crystallography (Fig. S1 and $\mathrm{S} 2 \dagger$ ). Reaction of the above-mentioned ligands with $\mathrm{Zn}$ (II) and $\mathrm{Cd}$ (II) salts in $\mathrm{DMF} / \mathrm{H}_{2} \mathrm{O}$ mixed solvents at $110{ }^{\circ} \mathrm{C}$ under autogenous pressure in an autoclave formed crystals 1 to $\mathbf{4}$, respectively. The FT-IR spectra of crystals $\mathbf{1}$ to $\mathbf{4}$ are shown in Fig. S3. $\uparrow$ The consistent PXRD patterns between experimental products and simulation confirmed the successful preparation and good phase purity of these compounds (Fig. S4†). Structural analysis shows that $\mathbf{1}$ crystallizes in a monoclinic system with space group $P 2_{1} / c$. The asymmetric unit consists of a $\mathrm{Zn}$ (II) ion, one $3-\mathrm{PBI}^{2-}$ ligand, one coordinated water molecule and two DMF molecules in the lattice. The central $\mathrm{Zn}(\mathrm{II})$ is five- coordinated by four oxygen atoms, three of which $(\mathrm{O} 1 \mathrm{~A}, 02 \mathrm{~A}$, $\mathrm{O} 3 \mathrm{~B})$ are from two equivalent $3-\mathrm{PBI}^{2-}$ ligands, $(\mathrm{O} 1 \mathrm{~W})$ is from a coordinated water molecule, and one nitrogen atom (N2) from another 3-PBI ${ }^{2-}$ ligands to furnish a distorted trigonal bipyramidal geometry. The $\mathrm{Zn}-\mathrm{O}$ bond lengths are in the range of 1.956(4)-2.043(5) A, which are consistent with the range of Znbased coordination polymers reported previously. ${ }^{30,31}$ As shown in Fig. 1a, adjacent $\mathrm{Zn}^{2+}$ ion sites are linked by $3-\mathrm{PBI}^{2-}$ ligands to generate a one-dimensional (1D) chain with a $\mathrm{Zn} \cdots \mathrm{Zn}$ distance of 10.016(1) $\AA$ (Fig. 1b). If the organic 3-PBI ${ }^{2-}$ ligand and $\mathrm{Zn}$ atoms act as trinodal geometry, this $1 \mathrm{D}$ chain could be described as a ladder-like chain (Fig. 1c). Moreover, the

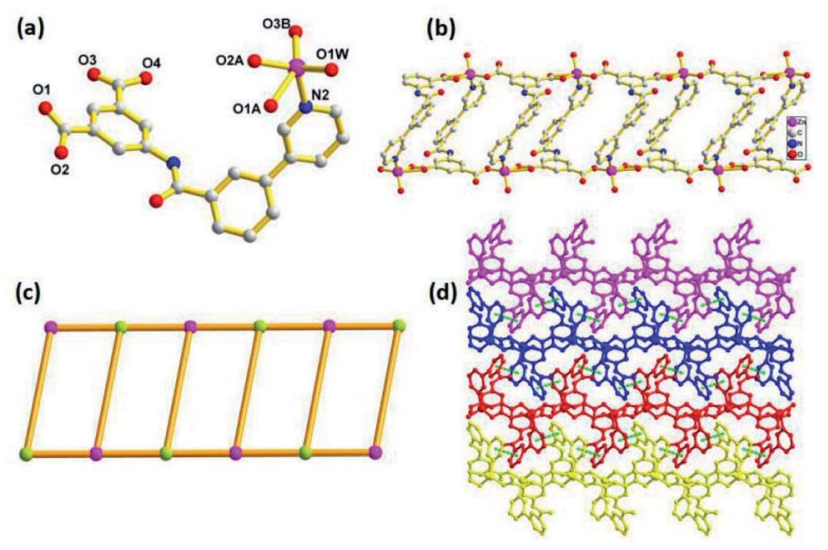

Fig. 1 Crystal structure of 1. (a) Coordination environment of $\mathrm{Zn}(॥)$ ion. Symmetry code, (A) $2-x, 2-y, 1-z$; (B) $2-x, 2-y, 2-z$. All H atoms are omitted for clarity. (b) 1D inorganic Zn-chain connected through $3-\mathrm{PBI}^{2-}$ ligands. (c) View of 1D coordination polymer ladders along $b$ axis. (d) 3D supramolecular architecture. 
neighboring ladder moieties are further connected to each other via face-to-face $\pi \cdots \pi$ stacking interactions with a distance of $3.784 \AA$ between the parallel benzene rings of the $3-\mathrm{PBI}^{2-}$ ligand, resulting in $2 \mathrm{D}$ layers in the $a b$ plane (Fig. S5 $\dagger$ ). Finally, the adjacent $2 \mathrm{D}$ layers are further extended into a $3 \mathrm{D}$ supramolecular structure through the interlayer $(\mathrm{O}-\mathrm{H} \cdots \mathrm{O})$ hydrogenbonding interactions (Fig. 1d).

Compound 2 also crystallizes in the monoclinic space group $P 2_{1} / c$. As illustrated in Fig. 2a, the coordination environment of Cd(II) shows a distorted octahedral geometry, defined by four oxygen atoms $(\mathrm{O} 1, \mathrm{O} 2,03 \mathrm{~A}, \mathrm{O} 4 \mathrm{~B})$ of three carboxylate groups, one nitrogen $(\mathrm{N} 2 \mathrm{C})$ of the pyridine ring from the $3-\mathrm{PBI}^{2-}$ ligands and one oxygen atom (O6) from one coordinated DMF molecule. Two adjacent $\mathrm{Cd}(\mathrm{II})$ ions are linked through the isophthalate groups of the 3-PBI ${ }^{2-}$ ligand, leading to the formation of $1 \mathrm{D}$ infinite linear chains along the $a$-axis with classical binuclear $\left[\mathrm{Cd}_{2}(\mathrm{COO})_{4}\right]$ secondary building units (SBUs). Additionally, the adjacent $\left[\mathrm{Cd}_{2}(\mathrm{COO})_{4}\right]$ SBUs are also combined with the pyridyl group of the ligands to constitute a unique 3D framework with a quadrilateral channel (Fig. 2b). After omitting DMF solvent molecules, PLATON analysis exhibits that the solvent accessible volume is $24.6 \%$ per unit cell volume [524.9/2134.9 $\left.\AA^{3}\right]$. The network topological approach by reducing a complicated structure to simple node-and-connector nets has been used extensively in the analyses of structures. Topologically, each 3$\mathrm{PBI}^{2-}$ ligand acts as a 3-connector and each Cd(II) unit plays the role of a 6-connecting node (Fig. 2c), resulting in the configuration of a $(3,6)$-connected rutile (rtl) net with the Schläfli symbol of $\left(4^{2} \cdot 6^{10} \cdot 8^{3}\right)\left(4 \cdot 6^{2}\right)_{2}$ simplified by the TOPOS program. ${ }^{32}$ In particular, it should be noted that compound 2 retains its

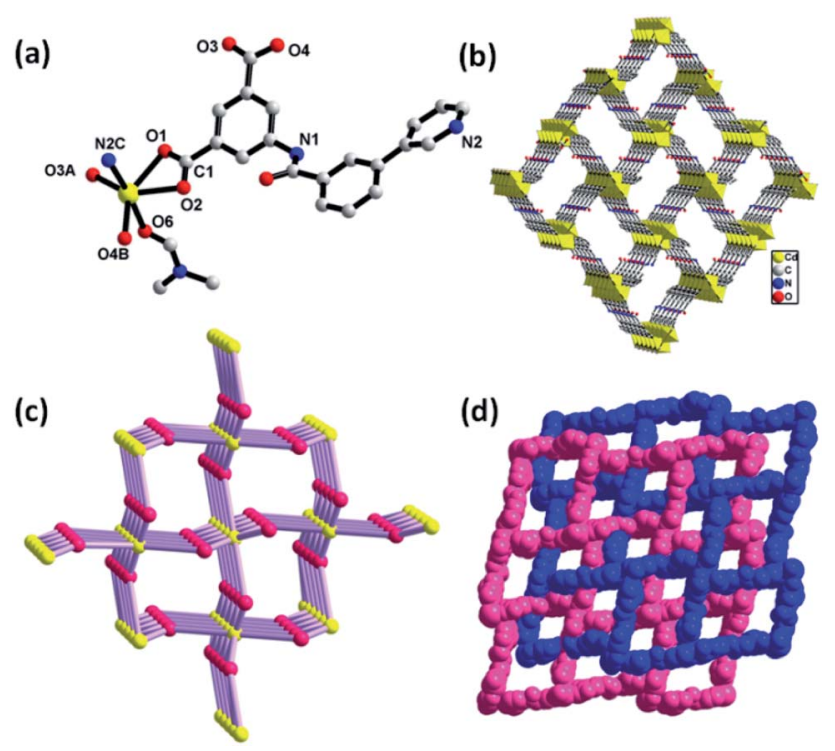

Fig. 2 Crystal structure of 2. (a) The coordination environment of the $\mathrm{Cd}($ II) ion. Symmetry code, (A) $1-x, 1-y,-z$; (B) $x, y,-1+z$; (C) $2-x$, $-0.5+y, 0.5-z$. (b) Polyhedral view of 3D network along the ab plane. (c) Schematic representation of the 3D rutile topology. (d) Schematic representation of the 2 -fold interpenetrating rutile topology. All hydrogen atoms are omitted for clarity. self-interpenetrating structure by interweaving two identical structures with each other to form a rutile array (Fig. 2d).

Compound 3 features a 3D framework and crystallizes in the monoclinic space group $C c$. As shown in Fig. 3a, the Zn1, Zn2, $\mathrm{Zn} 3$ and $\mathrm{Zn} 4$ ions are bridged by one $\mu_{4}-\mathrm{O}$ atom and six carboxylate groups to form a tetranuclear $\left[\mathrm{Zn}_{4}\left(\mu_{4}-\mathrm{O}\right)(\mathrm{COO})_{6}\right]$ cluster. In this moiety, Zn1(II), which is similar to Zn2(II) and Zn4(II) in its coordination environment, is five-coordinated with a distorted square pyramid geometry involving three oxygen atoms from two carboxylate groups, one $\mu_{4}-\mathrm{O}$ atom and one nitrogen atom. While the remaining Zn3(II) employs a fourcoordinated mode, showing a tetrahedral coordination environment with three oxygen atoms from carboxylate groups and one $\mu_{4}-\mathrm{O}$ atom. The adjacent $\left[\mathrm{Zn}_{4}\left(\mu_{4}-\mathrm{O}\right)(\mathrm{COO})_{6}\right]$ cluster is connected through the isophthalate groups of the 4- $\mathrm{PBI}^{2-}$ ligand, leading to the formation of a 3D framework with a onedimensional (1D) channel (Fig. 3b). Topologically, the connection of the centrosymmetric tetranuclear $\mathrm{Zn}$ cluster $\left[\mathrm{Zn}_{4}\left(\mu_{4^{-}}\right.\right.$ $\left.\mathrm{O})(\mathrm{COO})_{6}\right]$ serving as the hexatopic basic SBU and the ligand 4$\mathrm{PBI}^{2-}$ acting as a trinodal building block result in a threedimensional (3D) (3,6)-connected network topology, which can be described as a diamond net (Fig. 3c). On the other hand, it is interesting to find that each 4-PBI ${ }^{2-}$ ligand further links three the SBUs using its isophthalate groups and pyridine in the $\mu_{5}$ - (a)

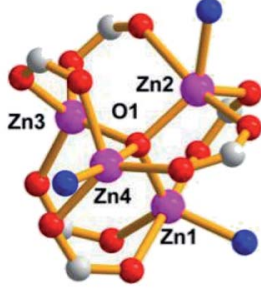

(c)

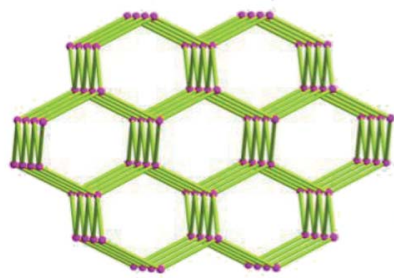

(e)

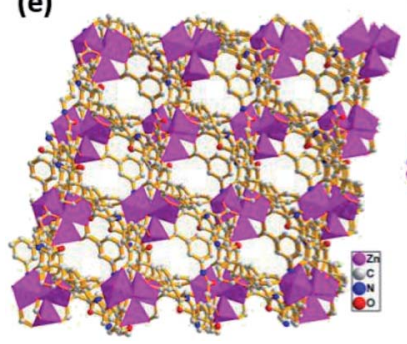

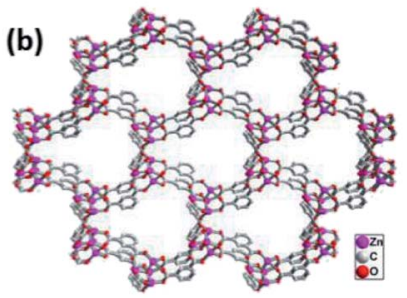

(d)

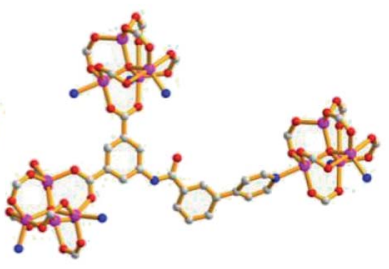

(f)
Fig. 3 Crystal structure of 3. (a) Coordination environment of Zn(॥) ions. (b) View of the 3D framework. (c) Topological view of the 3D diamond structure. (d) Coordination environment of the 4-PBI ${ }^{2-}$ ligand. (e) View of the intricate 3D structure constructed from zinc clusters and 4-PBI ${ }^{2-}$ ligands. (f) Topological view of the $3 \mathrm{D}(3,9)-$ connected network with the Schläfli symbol of $\left(4 \cdot 6^{2}\right)_{2}$ $\left(4 \cdot 2^{6} \cdot 2^{4} \cdot 8^{10}\right)_{2}\left(6^{3}\right)$ 
$\eta^{1}: \eta^{1}: \eta^{1}: \eta^{1}: \eta^{1}$ bridging mode to form a more intricate $(3,9)$ connected 3D network with the unusual Schläfli symbol of $\left(4 \cdot 6^{2}\right)_{2}\left(4 \cdot 2^{6} \cdot 2^{4} \cdot 8^{10}\right)_{2}\left(6^{3}\right)$ (Fig. 3d-f).

Compound 4 is classified as monoclinic with $C 2 / c$ space group. The metal Cd1(II), which is similar to Cd2(II), possesses a slightly distorted pentagonal bipyramidal geometry, in which four oxygen atoms $(\mathrm{O} 1, \mathrm{O} 2, \mathrm{O} 3 \mathrm{~A}, \mathrm{O} 4 \mathrm{~A})$ from bidentate chelating carboxyl groups, one nitrogen atom (N4) from pyridine located in the equatorial plane and two water molecules occupy the axial positions (Fig. 4a). The seven-coordinated Cd1(II) and $\mathrm{Cd} 2$ (II) anions are linked together by a $4-\mathrm{PBI}^{2-}$ ligand to generate a 2D layered structure (Fig. 4c), which can be seen as having $\left(4 \cdot 8^{2}\right)$ topology by simplifying the ligand as a 3-connected node and the Cd atom as a 3-connected node (Fig. 4d). However, there exists another distinct coordination mode in the structure. Both $\mathrm{Cd} 3$ (II) and $\mathrm{Cd} 4$ (II) are six-coordinated, surrounded by one pyridine nitrogen atom, four carboxylate oxygen atoms of four individual ligands and one water molecule (Fig. 4b). The two adjacent Cd3(II) and Cd4(II) atoms are linked

(a)

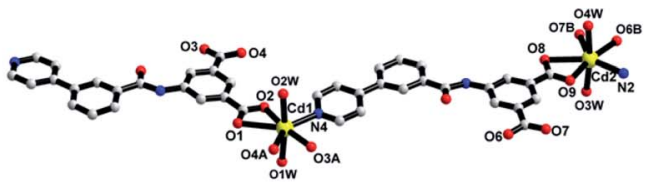

(b)

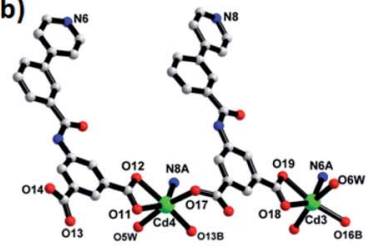

(d)

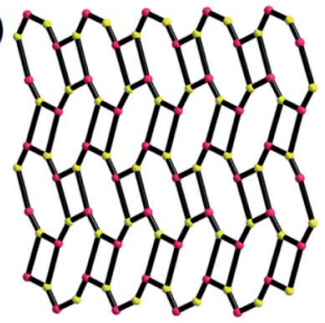

(f)

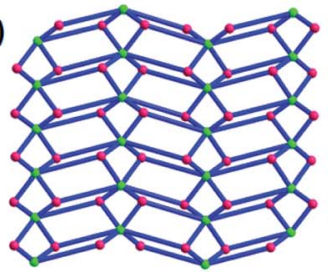

(c)

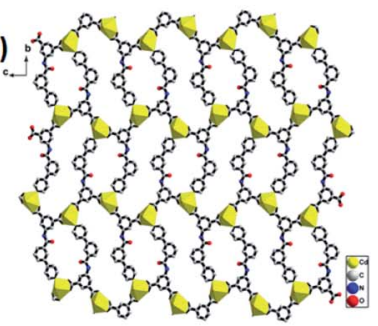

(e)

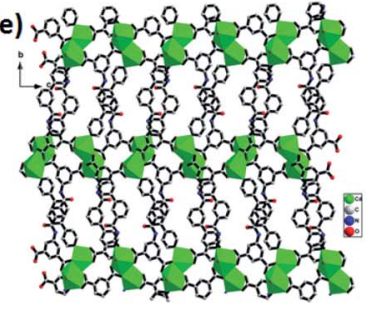

(g)

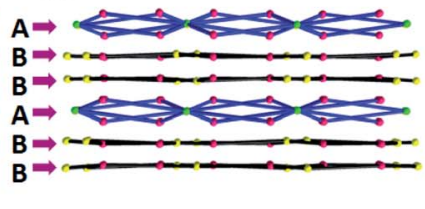

Fig. 4 Crystal structure of 4 . (a) Coordination environment of $\mathrm{Cd} 1$ (॥) and $\mathrm{Cd} 2$ (II) ions; symmetry code: (A) $x, 1-y, 0.5+z$; (B) $3-x,-y,-z$. (b) Coordination environment of $\mathrm{Cd} 3($ (I) and $\mathrm{Cd} 4($ (I) ions; symmetry code: (A) $1.5-x, 0.5-y, 2-z$; (B) $x, 1-y, 0.5+z$. (c) Polyhedral view of the $2 \mathrm{D}$ network constructed from $\mathrm{Cd} 1(\mathrm{I})$ and $\mathrm{Cd} 2(\mathrm{II})$. (d) $\left(4 \cdot 8^{2}\right)$ topology for the 2D layer constructed from $\mathrm{Cd} 1$ (II) and $\mathrm{Cd} 2$ (II). (e) View of the 2D layered structure constructed from Cd3(॥) and Cd4(॥) SBUs. (f) $(3,6)$-connected kgd topology 2D layer topology from $\mathrm{Cd} 3($ (I) and Cd4(I). (g) 2D layer stacked with ABBABB modes.

by an isophthalic acid group to generate binuclear $\left[\mathrm{Cd}_{2}(\mathrm{COO})_{4}\right]$ SBU and each SBU is further connected by $4-\mathrm{PBI}^{2-}$ to yield a $2 \mathrm{D}$ layered network (Fig. 4e). From the perspective of topological analysis, the layer can be described as a $2 \mathrm{D}(3,6)$-connected kgd topology with the Schläfli symbol of $\left(4^{3}\right)_{2}\left(4^{6} \cdot 6^{6} \cdot 8\right)$ (Fig. 4f). An appealing structural feature in compound 4 is that the $2 \mathrm{D}$ layers are stacked in the unusual ABBABB mode with two distinct topological structures (Fig. $4 \mathrm{~g}$, where A represents $\left(4 \cdot 8^{2}\right)$ topology and B denotes kgd topology) in the crystal structure.

Compounds 1-4 are synthesized via self-assembly with two isomeric polycarboxylate ligands under identical solvothermal conditions. However, these compounds possess totally different topologies and structures. Despite the carboxyl groups both being deprotonated and participating in coordination, different coordination modes of $3-\mathrm{PBI}^{2-}$ and $4-\mathrm{PBI}^{2-}$ ligands are a main factor in the structural diversity. For 1 , the $3-\mathrm{PBI}^{2-}$ ligand adopts a $\mu_{3}-\eta^{1}: \eta^{1}: \eta^{1}: \eta^{1}$ mode (Mode I, Scheme 2), connecting with three $\mathrm{Zn}$ (II) ions to produce a $1 \mathrm{D}$ ladder-like chain. In compound 2, each 3-PBI ${ }^{2-}$ ligand attaches four Cd(II) with $\mu_{4^{-}}$ $\eta^{1}: \eta^{1}: \eta^{1}: \eta^{1}: \eta^{1}$ coordination mode (Mode II), resulting in the formation of a $(3,6)$-connected rutile net. It is noteworthy that one $3 \mathrm{D}$ net interweaves with another identical one to construct a self-interpenetrating structure. In compound 3, each 4-PBI ${ }^{2-}$ ligand adopts $\mu_{5}-\eta^{1}: \eta^{1}: \eta^{1}: \eta^{1}: \eta^{1}$ (Mode III) to link Zn(II) ions via the bridging of a $\mu_{4}-\mathrm{O}$ group, leading to an infinite $(3,9)$-connected $3 \mathrm{D}$ network based on a tetranuclear $\left[\mathrm{Zn}_{4}\left(\mu_{4}-\mathrm{O}\right)(\mathrm{COO})_{6}\right]$ cluster. For compound $\mathbf{4}$, there are two different coordination modes of the 4- $\mathrm{PBI}^{2-}$ ligand. On one hand, a $2 \mathrm{D}$ layer with $\left(4.8^{2}\right)$ topology is obtained by the assembly of each $4-\mathrm{PBI}^{2-}$ ligand with $\mu_{3}-\eta^{1}: \eta^{1}: \eta^{1}: \eta^{1}: \eta^{1}$ (Mode IV). On the other hand, another $2 \mathrm{D}$ layer with $(3,6)$-connected kgd topology is attained by the construction of a $4-\mathrm{PBI}^{2-}$ ligand with $\mu_{3}-\eta^{1}: \eta^{1}: \eta^{1}: \eta^{1}$ (Mode V). It is also attractive and unusual that there are two distinct topologies stacked in one crystal structure with a remarkable ABBABB mode. A comparison of the structural features for these complexes suggests that the coordination preferences of the metals, the connectivity of the metal nodes as well as the binding modes and protonation behavior of $3-\mathrm{PBI}^{2-}$ and 4$\mathrm{PBI}^{2-}$ are responsible for the interesting architectural variations.

\section{Thermal analysis}

Thermal gravimetric analysis (TGA) under an $\mathrm{N}_{2}$ atmosphere was carried out to examine the thermal stabilities of compounds 1-4 (Fig. S6†). According to the TGA curve of 1, the first loss caused by the removal of two DMF and one water molecule is $27.83 \%$ (calcd $27.74 \%$ ) and the second loss starting

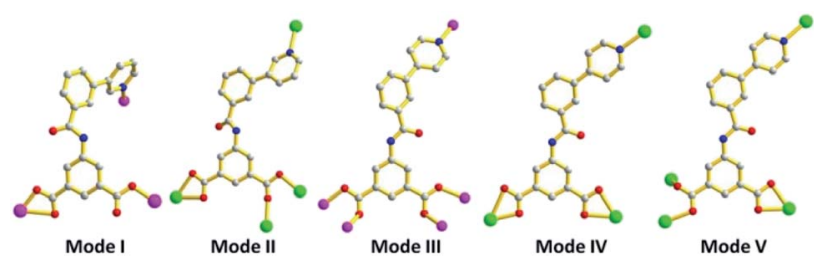

Scheme 2 Coordination modes of $3-\mathrm{PBI}^{2-}$ and $4-\mathrm{PBI}^{2-}$ ligands in compounds 1-4. 

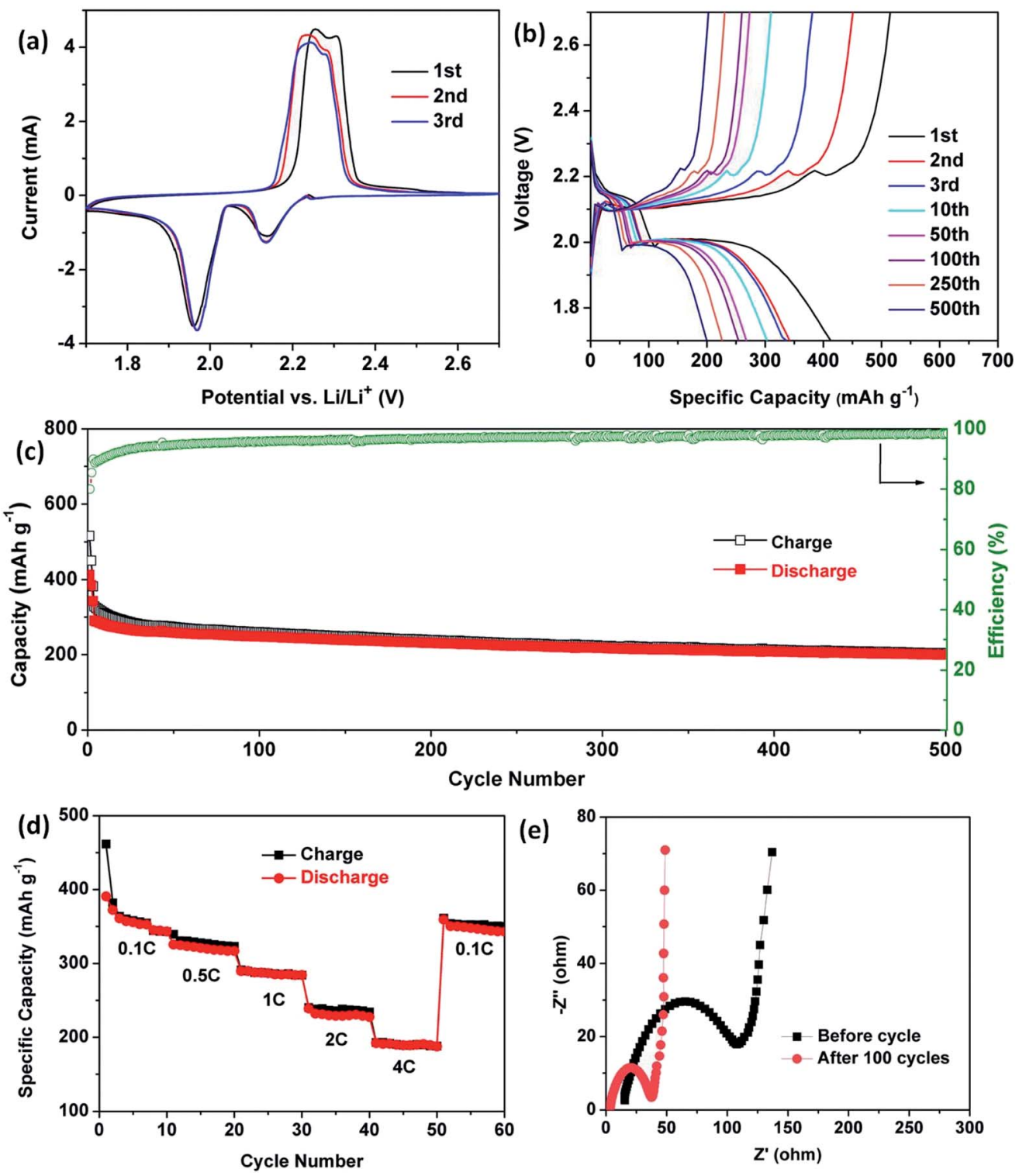

Fig. 5 Electrochemical performance of the Cd-CP/Se electrode. (a) CV curves of the initial three cycles. (b) Charge-discharge voltage profiles. (c) Cycling stability at current rate of $1 \mathrm{C}$. (d) Rate performance at different current densities from $0.1 \mathrm{C}$ to $4 \mathrm{C}$. (e) Electrochemical impedance spectra (EIS) before and after the cycling test.

from $450{ }^{\circ} \mathrm{C}$ can be attributed to the decomposition of the whole framework. Compound 2 undergoes weight loss in the range of $120-260{ }^{\circ} \mathrm{C}$ (the loss of a coordinated guest DMF molecule, exp $13.26 \%$, calcd $13.34 \%$ ) and $350-600{ }^{\circ} \mathrm{C}$, respectively. As for 3, the removal of three DMF molecules (exp 13.14\%, calcd 13.84\%) corresponds to the slope from 100 to $250{ }^{\circ} \mathrm{C}$. Compound 4 releases nineteen water molecules (six coordinated and thirteen lattice $\mathrm{H}_{2} \mathrm{O}$ molecules) in the range of 30 to $150{ }^{\circ} \mathrm{C}(\exp 15.08 \%$, calcd $15.27 \%$ ); then a sharp weight loss emerges at $300{ }^{\circ} \mathrm{C}$ due to framework disintegration.

\section{Electrochemical performance for lithium storage}

Over past decades, porous coordination polymers, such as ZIF8 and MIL-101, have been developed as cathode hosts for $\mathrm{Li}-\mathrm{S}, \mathrm{Li}-$ Se and Li-ion batteries due to their structural porosity and functional modifiability. ${ }^{32-35} \quad \mathrm{~N}_{2}$ adsorption/desorption isotherms of compound 2 show typical type-I microporous characteristics with a surface area of $514 \mathrm{~m}^{2} \mathrm{~g}^{-1}$ (Fig. S7†). Owing to the porosity of compound 2 (donated as Cd-CP), herein, we mixed and ground selenium powder with $\mathrm{Cd}-\mathrm{CP}$ samples under thermal treatment to generate $\mathrm{Cd}-\mathrm{CP} / \mathrm{Se}$, which was then evaluated as a cathode material.

For the purpose of understanding the redox reaction of selenium in the electrode, cyclic voltammetry profiles of $\mathrm{Cd}-\mathrm{CP} /$ Se electrodes were first recorded in a voltage window from 1.7 to $2.7 \mathrm{~V}$ at a sweep rate of $0.1 \mathrm{mV} \mathrm{s}^{-1}$. As depicted in Fig. 5a, two pairs of redox peaks can be observed in the $\mathrm{CV}$ curves, indicating two-step phase transitions during the charge/discharge processes. This phenomenon could be observed in other ether-based electrolytes reported previously. ${ }^{36,37}$ The reduction peaks, which appeared at 2.13 and $1.97 \mathrm{~V}$, unambiguously attest 
to the reactions between selenium and lithium in the discharging procedure. Se reduces to polyselenide $\mathrm{Li}_{2} \mathrm{Se}_{n}(n \geq 4)$, then further reduces to $\mathrm{Li}_{2} \mathrm{Se}$ in the lithiation process. Cathodic peaks of the first cycle located at $2.25 \mathrm{~V}$ and $2.30 \mathrm{~V}$ show that $\mathrm{Li}_{2} \mathrm{Se}$ converts to $\mathrm{Li}_{2} \mathrm{Se}_{2}$ and $\mathrm{Se}$ in the delithiation process, respectively. ${ }^{38-39}$ Then, the cathodic peaks move slightly to 2.23 and $2.28 \mathrm{~V}$ and run similarly in subsequent cycles, suggesting that reversible reactions occur stably in the $\mathrm{Cd}-\mathrm{CP} / \mathrm{Se}$ electrode and the porous structure can provide a good cycling stability and improved coulombic efficiency during the subsequent cycles.

Galvanostatic discharge-charge measurements were carried out at $1 \mathrm{C}$ in the voltage range between $1.7 \mathrm{~V}$ and $2.7 \mathrm{~V}$ at $25^{\circ} \mathrm{C}$ to estimate the lithium storage properties of Cd-CP/Se. Fig. $5 b$ shows the charge-discharge voltage profiles for different cycles at the $1 \mathrm{st}, 2 \mathrm{nd}, 3 \mathrm{rd}, 10 \mathrm{th}, 50 \mathrm{th}, 100 \mathrm{th}, 250 \mathrm{th}$, and 500th cycles of the Cd-CP/Se cathode. Two representative plateaus of selenium at $2.14 \mathrm{~V}$ and $1.99 \mathrm{~V}$ were observed in the discharge curves, which is perfectly consistent with the result of the CV test. The cycling performance and the coulombic efficiency of $\mathrm{Cd}-\mathrm{CP} / \mathrm{Se}$ composite were tested. As presented in Fig. $5 \mathrm{c}$, the $\mathrm{Cd}-\mathrm{CP} / \mathrm{Se}$ cathode delivers an initial discharge capacity of $514 \mathrm{~mA} \mathrm{~h} \mathrm{~g}^{-1}$ at $1 \mathrm{C}\left(1 \mathrm{C}=675 \mathrm{~mA} \mathrm{~g}^{-1}\right)$, demonstrating a relatively high utilization of active materials. As the number of cycles increases, the specific capacity decays slowly and remains at $200 \mathrm{~mA} \mathrm{~h} \mathrm{~g}{ }^{-1}$ after 500 cycles with a coulombic efficiency of $98 \%$, indicating the stability of the cycle life performance.

To investigate the current density endurance of the $\mathrm{Cd}-\mathrm{CP} / \mathrm{Se}$ cathode, rate performances were evaluated to gain further insight into its electrochemical performance (Fig. 5d). The cointype cells were charged and discharged at $0.1,0.5,1,2$, and $4 \mathrm{C}$ for 10 cycles each. Correspondingly, the cathode delivers reversible capacities of $352,326,286,234,190 \mathrm{~mA} \mathrm{~h} \mathrm{~g}{ }^{-1}$, respectively. When the current density is reduced to $0.1 \mathrm{C}$ again, the reversible capacity of $351 \mathrm{~mA} \mathrm{~h} \mathrm{~g}^{-1}$ can be recovered, showing that the structure of the $\mathrm{Cd}-\mathrm{CP} / \mathrm{Se}$ cathode is not destroyed in high rate cycling. Moreover, the effect of $\mathrm{Cd}-\mathrm{CP} / \mathrm{Se}$ electrode kinetics was investigated by electrochemical impedance spectroscopy (EIS). As shown in Fig. 5e, the spectra have overlapped semicircles in the medium-frequency regions and straight lines in the low-frequency zone. Semicircles of the plot are commonly used to define electrode charge transfer resistance $\left(R_{\mathrm{ct}}\right){ }^{\mathbf{4 0 , 4 1}}$ Significantly, the Cd-CP/Se electrode after 100 cycles showed lower $R_{\text {ct }}$ values than those before cycling, indicating the enhanced charge transfer ability and electron transfer kinetics of the Cd-CP/Se electrode. ${ }^{42}$

\section{Conclusions}

In summary, four new coordination polymers, $\left\{\left[\mathrm{Zn}(3-\mathrm{PBI})\left(\mathrm{H}_{2}-\right.\right.\right.$ $\mathrm{O})] \cdot 2 \mathrm{DMF}\}_{n}$ (1), $[\mathrm{Cd}(3-\mathrm{PBI})(\mathrm{DMF})]_{n}(2), \quad\left\{\left[\mathrm{Zn}_{4}\left(\mu_{4}-\mathrm{O}\right)(4-\mathrm{PBI})_{3}\right]\right.$. $3 \mathrm{DMF}_{n} \quad$ (3), $\left\{\left[\mathrm{Cd}_{4}(4-\mathrm{PBI})_{4}\left(\mathrm{H}_{2} \mathrm{O}\right)_{6}\right] \cdot 13 \mathrm{H}_{2} \mathrm{O}\right\}_{n} \quad$ (4), were solvothermally synthesized by $\mathrm{Zn}(\mathrm{II}), \mathrm{Cd}(\mathrm{II})$ metal ions and two isomeric ligands $\left(3-\mathrm{H}_{2} \mathrm{PBI}, 4-\mathrm{H}_{2} \mathrm{PBI}\right)$, respectively. Differences in coordination abilities among metal ions and ligands result in distinct topological structures among these compounds. 1 features a 1D ladder-like chain, 2 possesses two interweaved structures making a (3,6)-connected rutile net, 3 exhibits a rare $(3,9)$-connected 3D network, while 4 has $2 \mathrm{D}\left(4 \cdot 8^{2}\right)$ topology and 2D (3,6)-connected kgd topology in the same crystal structure. In addition, compound 2 has the potential to be a cathode host for Li-Se cells, showing advanced storage performance.

\section{Conflicts of interest}

There are no conflicts to declare.

\section{Acknowledgements}

This work was supported by financial support from the National Natural Science Foundation of China (Grant No. 21671071 and 21471061), China Postdoctoral Science Foundation Funding (2018M643069), Fundamental Research Funds for the Central Universities, China (2018MS41), Science and Technology Planning Project of Guangdong Province (2017A010104015, 2017B090917002 and 2015B010135009), Innovation Team Project of Guangdong Ordinary University (No. 2015KCXTD005), the Great Scientific Research Project of Guangdong Ordinary University (No. 2016KZDXM023), and Open Project of State Key Laboratory of Supramolecular Structure and Materials (sklssm2019018).

\section{Notes and references}

1 M. Pan, Z. W. Wei, Y. W. Xu and C.-Y. Su, Prog. Chem., 2017, 1, 47-74.

2 L. Chen, J.-W. Ye, H.-P. Wang, M. Pan, S.-Y. Yin, Z.-W. Wei, L.-Y. Zhang, K. Wu, Y.-N. Fan and C.-Y. Su, Nat. Commun., 2017, 8, 15985.

3 J.-M. Chen, Y.-X. Hou, Q.-K. Zhou, H. Zhang and D. Liu, CrystEngComm, 2017, 19, 2603-2607.

4 J.-M. Chen, Q.-K. Zhou, Y.-X. Hou and D. Liu, CrystEngComm, 2017, 19, 6778-6786.

5 J.-M. Chen, Y.-X. Hou, Q.-K. Zhou, H. Zhang and D. Liu, Dalton Trans., 2017, 46, 9755-9759.

6 A. Kobayashi, K. Shimizu, A. Watanabe, Y. Nagao, N. Yoshimura, M. Yoshida and M. Kato, Inorg. Chem., 2019, 58, 2413-2421.

7 J. Liu, L. Chen, H. Cui, J. Zhang, L. Zhang and C.-Y. Su, Chem. Soc. Rev., 2014, 43, 6011-6061.

8 Z.-A. Zong, C.-B. Fan, X. Zhang, X.-M. Meng, F. Jin and Y.-H. Fan, CrystEngComm, 2019, 21, 673-686.

9 L. Fu, Y. Liu, M. Pan, X.-J. Kuang, C. Yan, K. Li, S.-C. Wei and C.-Y. Su, J. Mater. Chem. A, 2013, 1, 8575-8580.

10 C.-H. Zeng, J.-L. Wang, Y.-Y. Yang, T.-S. Chu, S.-L. Zhong, S. W. Ng and W.-T. Wong, J. Mater. Chem. C, 2014, 2, 2235-2242.

11 L. Yu, X. Wang, M. Cheng, H. Rong, Y. Song and Q. Li, Cryst. Growth Des., 2018, 18, 280-285.

12 L.-S. Long, CrystEngComm, 2010, 12, 1354-1365.

13 M.-L. Han, X.-H. Chang, X. Feng, L.-F. Ma and L.-Y. Wang, CrystEngComm, 2014, 16, 1687-1695. 
14 G.-X. Wen, M.-L. Han, X.-Q. Wu, Y.-P. Wu, W.-W. Dong, J. Zhao, D.-S. Li and L.-F. Ma, Dalton Trans., 2016, 45, 15492-15499.

15 M.-L. Han, G.-X. Wen, W.-W. Dong, Z.-H. Zhou, Y.-P. Wu, J. Zhao, D.-S. Li, L.-F. Ma and X.-H. Bu, J. Mater. Chem. C, 2017, 5, 8469-8474.

16 X. W. Liu, T. J. Sun, J. L. Hu and S. D. Wang, J. Mater. Chem. A, 2016, 4, 3584-3616.

17 Z. Zhu, L. S. Cui, C. B. Fan, X. Y. Zhang, D. M. Zhang, F. Jin and Y. H. Fan, Polyhedron, 2017, 133, 374-382.

18 X.-M. Lin, T.-T. Li, L.-F. Chen, L. Zhang and C.-Y. Su, Dalton Trans., 2012, 41, 10422-10429.

19 X.-M. Lin, T.-T. Li, Y.-W. Wang, L. Zhang and C.-Y. Su, Chem.-Asian J., 2012, 7, 2796-2804.

20 L. Hu, X.-J. Hong, X.-M. Lin, J. Lin, Q.-X. Cheng, B. Lokesh and Y.-P. Cai, Cryst. Growth Des., 2018, 18, 7088-7093.

21 H.-J. Peng, G.-X. Hao, Z.-H. Chu, J. Lin, X.-M. Lin and Y.-P. Cai, Cryst. Growth Des., 2017, 17, 5881-5886.

22 J.-L. Niu, H.-J. Peng, C.-H. Zeng, X.-M. Lin, P. Sathishkumar, Y.-P. Cai and A.-W. Xu, Chem. Eng. J., 2018, 336, 510-517.

23 X. M. Lin, J. Lin, J. L. Niu, J. J. Lan, R. C. K. Reddy, Y. P. Cai, J. C. Liu and G. Zhang, Mater. Chem. Front., 2018, 2, 22542262.

24 H.-J. Peng, G.-X. Hao, Zh.-H. Chu, Y.-W. Lin, X.-M. Lin and Y.-P. Cai, RSC Adv., 2017, 7, 34104-34109.

25 X.-M. Lin, J.-L. Niu, J. Lin, L.-M. Wei, L. Hu, G. Zhang and Y.-P. Cai, Inorg. Chem., 2016, 57, 8244-8247.

26 L. Hu, G. X. Hao, H. D. Luo, C. X. Ke, G. Shi, J. Lin, U. Qazi, X. M. Lin and Y. P. Cai, Cryst. Growth Des., 2018, 18, 28832889.

27 J. L. Niu, G. X. Hao, J. Lin, X. B. He, P. Sathishkumar, X. M. Lin and Y. P. Cai, Inorg. Chem., 2017, 56, 9966-9972.
28 G. M. Sheldrick, Acta Crystallogr., Sect. C: Struct. Chem., 2015, 71, 3-8.

29 A. L. Spek, Acta Crystallogr., Sect. C: Struct. Chem., 2015, 71, 9-18.

30 J. X. Xiao and D. Y. Ma, Inorg. Chim. Acta, 2018, 483, 6-11.

31 M. Armaghan, R. J. Niu, Y. Liu, W. H. Zhang, T. S. Andy Hor and J. P. Lang, Polyhedron, 2018, 153, 218-225.

32 V. A. Blatov, A. P. Shevchenko and D. M. Proserpio, Cryst. Growth Des., 2014, 14, 3576-3586.

33 W. Ye, W. Li, K. Wang, W. Yin, W. Chai, Y. Qu, Y. Rui and B. Tang, J. Phys. Chem. C, 2019, 123, 2048-2055.

34 Q. He, J. S. Liu, Z. H. Li, Q. Li, L. Xu, B. X. Zhang, J. S. Meng, Y. Z. Wu and L. Q. Mai, Small, 2017, 13, 1701504.

35 H. Li, M. Liang, W. W. Sun and Y. Wang, Adv. Funct. Mater., 2016, 26, 1098-1103.

36 J. S. Meng, C. J. Niu, L. H. Xu, J. T. Li, X. Liu, X. P. Wang, Y. Z. Wu, X. M. Xu, W. Y. Chen, Q. Li, Z. Z. Zhu, D. Y. Zhao and L. Q. Mai, J. Am. Chem. Soc., 2017, 139, 8212-8221.

37 M. Barghamadi, A. S. Best, A. I. Bhatt, A. F. Hollenkamp, M. Musameh, R. J. Rees and T. Rüther, Energy Environ. Sci., 2014, 7, 3902-3920.

38 S. Moon, Y. H. Jung, W. K. Jung, D. S. Jung, J. W. Choi and D. K. Kim, Adv. Mater., 2013, 25, 6547-6553.

39 Y. Yin, S. Xin, Y. Guo and L. Wan, Angew. Chem., Int. Ed., 2013, 52, 13186-13200.

40 S. K. Park, G. D. Park, D. Ko, Y. C. Kang and Y. Piao, Chem. Eng. J., 2017, 315, 355-363.

41 X. Peng, L. Wang, X. Zhang, B. Gao, J. Fu, S. Xiao, K. Huo and P. K. Chu, J. Power Sources, 2015, 288, 214-220.

42 S. K. Park, J. Lee, T. Hwang and Y. Piao, J. Mater. Chem. A, 2017, 5, 975-981. 